\title{
Ilizarov method in the treatment of children with periarticular fractures
}

\author{
A.A. Korobeinikov ${ }^{1,2}$, A.M. Aranovich ${ }^{1}$, D.A. Popkov ${ }^{1}$
}

${ }^{1}$ Ilizarov National Medical Research Centre for Traumatology and Orthopedics, Kurgan, Russian Federation

${ }^{2}$ Kurgan Regional Children's Clinical Hospital named after the Red Cross, Kurgan, Russian Federation

\begin{abstract}
Introduction Periarticular injuries in children include types I and II fractures according to the Salter-Harris classification and metaphyseal fractures. In most cases, conservative treatment is an effective method, but in some cases, surgical treatment, including external fixation, is the method of choice. Purpose Discussion of the principles of using the Ilizarov apparatus in the treatment of children with periarticular fractures of various locations, its advantages and disadvantages. Materials and methods We present the principles and features of the Ilizarov surgical techniques for treatment of children with periarticular fractures of the distal humerus, femur, radius and tibia. Discussion The methods of osteosynthesis for pediatric periarticular fractures imply transphyseal introduction of fixators that have a potential threat of iatrogenic damage to the growth plate in contrast to external fixation which performance implies that transosseous elements do not injure the growth zone, providing stable fixation of bone fragments in combination with early functional recovery of the damaged segment which is a key advantage over other methods. Conclusion The use of the Ilizarov apparatus enables to achieve the desired result in the treatment of pediatric periarticular fractures and has a number of advantages over other methods of surgical treatment.
\end{abstract}

Keywords: children, periarticular fractures, humerus, femur, tibia, radius, Ilizarov method

\section{INTRODUCTION}

In the literature, the concept of periarticular or juxta-articular (JAP) fractures in children unifies types I and II fractures according to the SalterHarris classification (SH I, II) and fractures of the metaphysis [1-6]. There is also a term "juxtaepiphyseal" and "extra-articular physeal" fracture [3, 7-9]. In these injuries, the fracture line passes through the growth plate in the horizontal plane, causing its partial (SH II) or complete (SH I) damage, while the germinal zone of the physis remains intact and the subsequent growth of the bone is unaffected in contrast to intra-articular fractures (SH III, IV, V). In cases of metaphyseal fractures of long bones in children, especially comminuted ones, damage to the growth plate is also possible $[3,7,9]$.

Juxta-articular pediatric fractures are common injuries associated with forced bending and rotation as a result of falls and sports injuries, as well as high-energy trauma [7, 9-11]. In most cases, SH I or SH II fractures and almost all simple uncomplicated metaphyseal fractures are treated with closed manual reduction and immobilization with a plaster cast $[8$, 12-14]. Complications in these cases are rare because of a relatively rapid fracture consolidation and high potential for growing bone remodeling, especially in young children [2, 15-19]. However, there are a number of indications for surgical treatment of these fractures. Bohn et al [2] argue that the periarticular nature of the fractures is associated with a high risk of early (secondary displacement, improper union, contracture) and late (limb shortening, angular deformity) complications. Juxta-articular fractures are often associated with damage to the skin, nerves, and ligaments $[4,12,15,20-22]$. Comminuted and/or open periarticular fractures are complex injuries, often requiring a surgical approach, which can cause certain difficulties for the doctor during treatment [23, 24]. The goal of surgical treatment of all extra-articular fractures is to achieve bone consolidation in an anatomically correct position with a good functional outcome, including early mobilization of the injured limb and restoration of its supportability [4-6,21,25]. Therefore, certain requirements dictated by the childhood must be met: exclusion of iatrogenic significant damage to the growth plate, adequate reduction, minimal surgical aggression, ensuring stability of fixation even with a comminuted fracture, early restoration of the function of the damaged segment and the general activity of the child. These requirements present certain limitations for the surgeon in choosing the method of surgical treatment. The small size of one of the bone fragments limits the surgeon's choice of a fixator [18, 19, 26-28]. All of the above excludes the use of traditional internal fixators [13, 16, 29-33].

External fixation foresees the introduction of transosseous elements at different angles without affecting the growth plate. The classical transosseous elements of the Ilizarov apparatus are wires with a diameter of 1.5-1.8 $\mathrm{mm}$ that provide stable fixation of even small fragments [4, 21, 23, 34].

The purpose of the study was to discuss the principles of using the Ilizarov apparatus in the treatment of children with juxta-articular fractures of various locations. 


\section{MATERIAL AND METHODS}

\section{Periarticular fractures of the distal humerus (supracondylar fractures)}

Surgical technique Skeletal traction on the operation table is performed through the olecranon to eliminate rotation and angulation of bone segments as step one (Fig. 1).
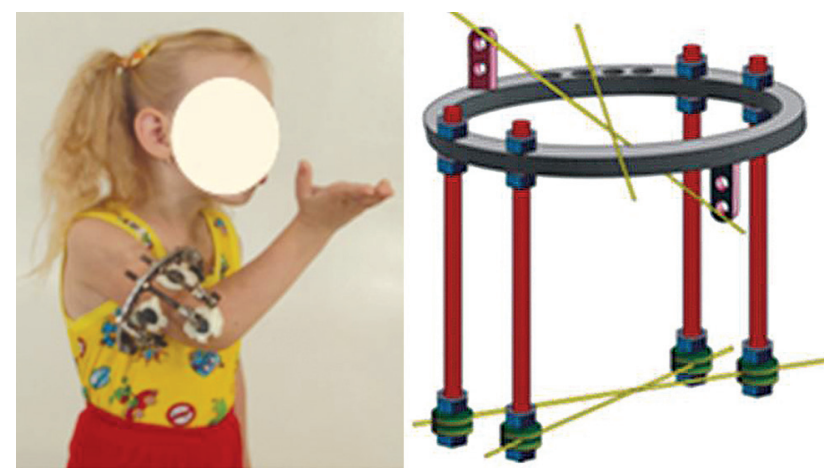

Fig. 1 Patient with the Ilizarov apparatus on the humerus and the diagram of its minimal assembly

Intraoperative $\mathrm{X}$-ray control (C-arm) is required for accurate insertion of transosseous elements. Thin wires may be inserted into the skin as landmarks along the anterior and lateral surface of the humerus at the level of the planned introduction of the transosseous elements. It will reduce the number of intraoperative $\mathrm{X}$-ray examinations. Upon satisfactory reduction of the fragments and correct location of the wire markers, transosseous elements are inserted. Preference is given to wires with a diameter of 1.5 and $1.8 \mathrm{~mm}$. The number of supports of the Ilizarov frame depends primarily on the age of the patient. In preschool children, a "lightweight" version of the Ilizarov apparatus can be used: one ring support is used at the level of the proximal fragment and the transosseous elements that pass through the distal fragment are fixed on threaded rods (Fig. 1). Thus, it is possible to reduce the weight of the frame and improve the radiological visualization of the position of the fragments (Fig. 2).
In children of school age and older, the requirements for the stability of bone fragments are higher. Therefore, the Ilizarov frame consists of 3 supports with the distal fragment fixed on a half-ring or 3/4 of the ring for providing an open sector along the anterior surface to maintain movements in the elbow joint in the postoperative period.

In children with supracondylar fractures, the Ilizarov method allows one-stage closed reduction, stable fixation of bone fragments, even in a comminuted fracture, and provides early functional recovery.

We recommend Ilizarov transosseous osteosynthesis in children with supracondylar fractures as the method of choice for severe open and/ or comminuted fractures, fractures that are difficult to reduce, or for cases of secondary displacement after wire osteosynthesis.

\section{Periarticular fracture of the distal radius}

The standard surgical technique is to pass 2 wires through the proximal ulnar and one wire through both bones of the forearm. The wires are tensioned and fixed in a ring support that is perpendicular to the axis of the forearm. The distal wire is passed through the metacarpal bones 2 to 5 and fixed in a half-ring support. The supports are connected with threaded rods including an intermediate support, which is located 2-3 cm proximal to the fracture line (Fig. 3). Distraction is performed between the distal ring and the distal half-ring to eliminate the displacement along the length. Usually, only two wires are passed through the distal fragment of the radius: the olive wire is drawn parallel to the growth plate from lateral to medial, and the cantilever olive wire is drawn in the anteroposterior direction, the latter passes only the thickness of the bone, without going beyond the anterior cortex. The wires are fixed to a ring support through posts of the required size. The final reduction is performed using a wire passed through the distal part of the proximal fragment.
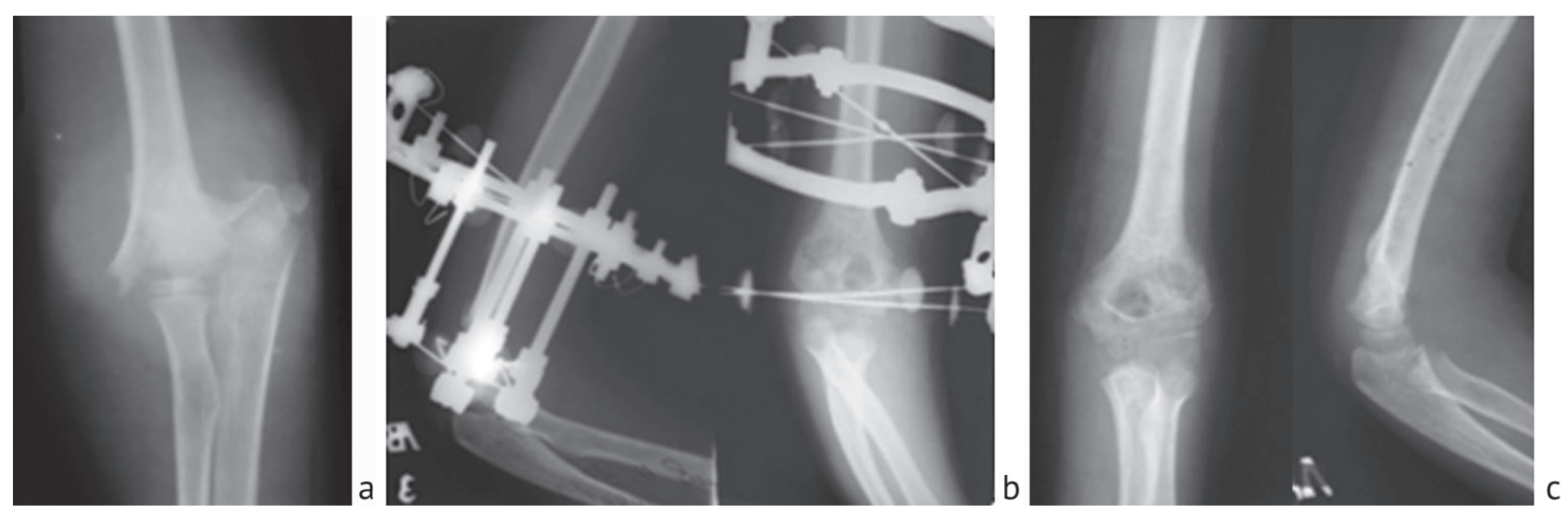

Fig. 2 Closed supracondylar fracture of the humerus (Garland III): $\boldsymbol{a}$ X-ray of the fracture zone before surgery; $\boldsymbol{b}$ radiographs in two projections after Ilizarov osteosynthesis; $\boldsymbol{c}$ X-rays taken in two projections after dismantling the Ilizarov apparatus 

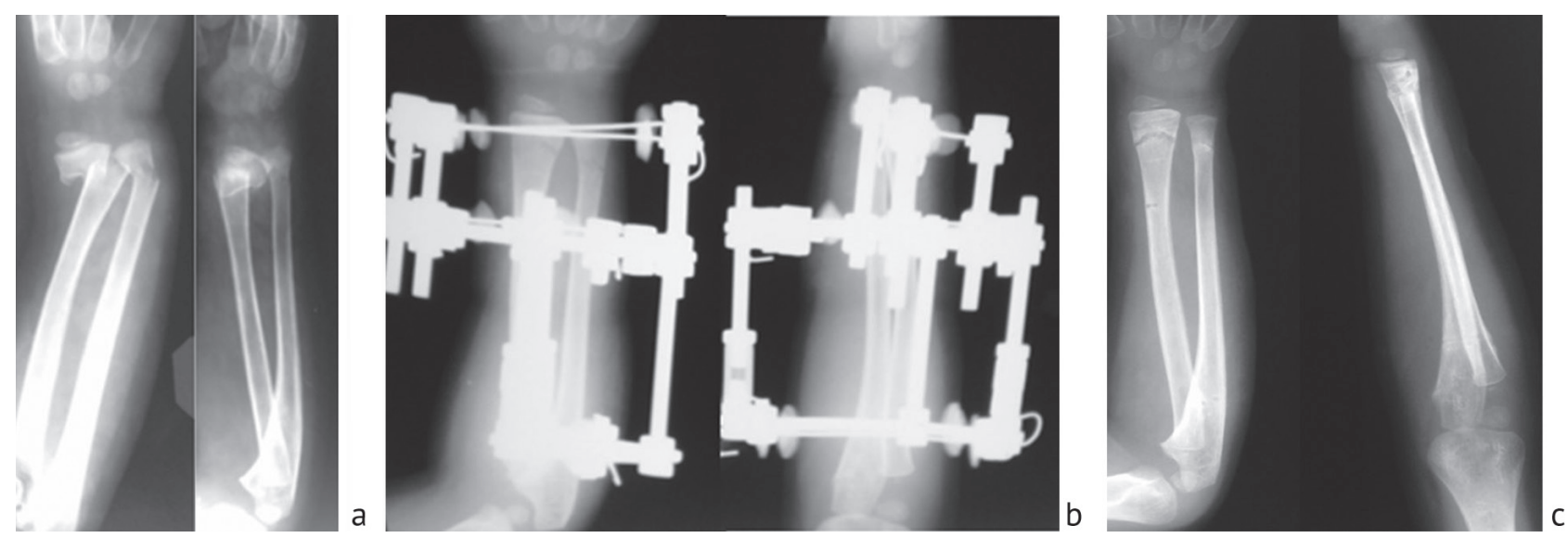

Fig. 3 Closed fracture of the distal metaphysis of the forearm (SH II). Radiographs of the fracture area taken in two projections: $\boldsymbol{a}$ before the operation; $\boldsymbol{b}$ after osteosynthesis according to Ilizarov; $\boldsymbol{c}$ after dismantling the Ilizarov apparatus

Upon radiographic checks of satisfactory position of the fragments, distraction forces in the contour of the apparatus are released. Given the small size of the distal fragment, fixation of the wrist joint is continued until the edema and pain are relieved, usually for 7-10 days, after which the wire passed through the metacarpal bones is removed, and the child begins active motions of the wrist joint. We have never noticed difficulty in regaining movements. Moreover, the Ilizarov technique allows preserving function in patients with bilateral distal radial fractures.

The advantages of external fixation in the treatment of these injuries are the early functional restoration of the injured forearm without loss of fixation stability of fragments in comparison with the conservative method and wire osteosynthesis [4, 27]. Besides, the wires passed through the epiphysis do not cross the growth plate, excluding its additional iatrogenic damage.

\section{Periarticular fractures of the distal femur}

Gross displacements are eliminated by traction on the operating table with a wire that is passed through the epiphysis of the femur or the tuberosity of the tibia. Intraoperative X-ray control (C-arm) is necessary to determine the exact position of the transosseous elements (wires, Schanz screws). The assembly of the Ilizarov apparatus includes 3 supports. The proximal support must have at least three wires or two Schanz screws attached at an angle to each other. The use of Schanz screws allows mounting of a smaller size support, what is more comfortable for the patient. In the middle support, two wires are usually sufficient that cross 5-6 cm above the fracture line. Supports are mounted perpendicular to the anatomical axis of the femur. The anatomy of the femur allows three wires (including the traction wire) to be passed through the epiphysis. The wires, being tensioned, are fixed to the distal ring support. The final reduction is performed with known reduction techniques using reductionfixation wires in the middle support or by manipulating ring supports (Fig. 4). In a concomitant damage to the knee joint soft tissues, it is necessary to mount the module on the lower leg and fix the knee joint.

\section{Periarticular fractures of the distal tibia}

As in fractures of the distal femur, the surgical technique for distal juxta-articular tibial fractures involves traction on the operation table for performing primary reduction. A module of two ring supports is mounted on the proximal fragment. At the level of each support, at least two wires are crossed and fixed being tensed on the supports. The wires passing through the distal epiphysis are inserted strictly parallel to the growth plate, without crossing the latter, and are fixed in the distal support (Fig. 5). Reduction is performed using well-known reduction maneuvers.
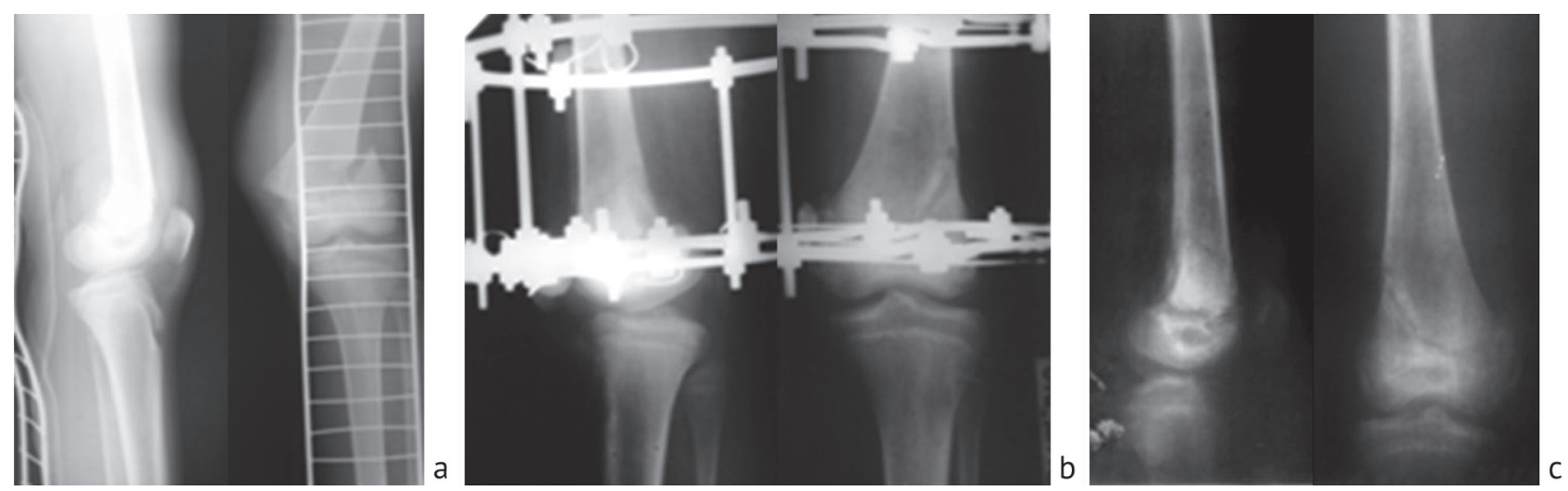

Fig. 4 Closed fracture of the distal epimetaphysis of the femur (SH II). Radiographs taken in two projections: $\boldsymbol{a}$ before the operation; $\boldsymbol{b}$ after Ilizarov osteosynthesis; $\boldsymbol{c}$ after dismantling the Ilizarov apparatus 

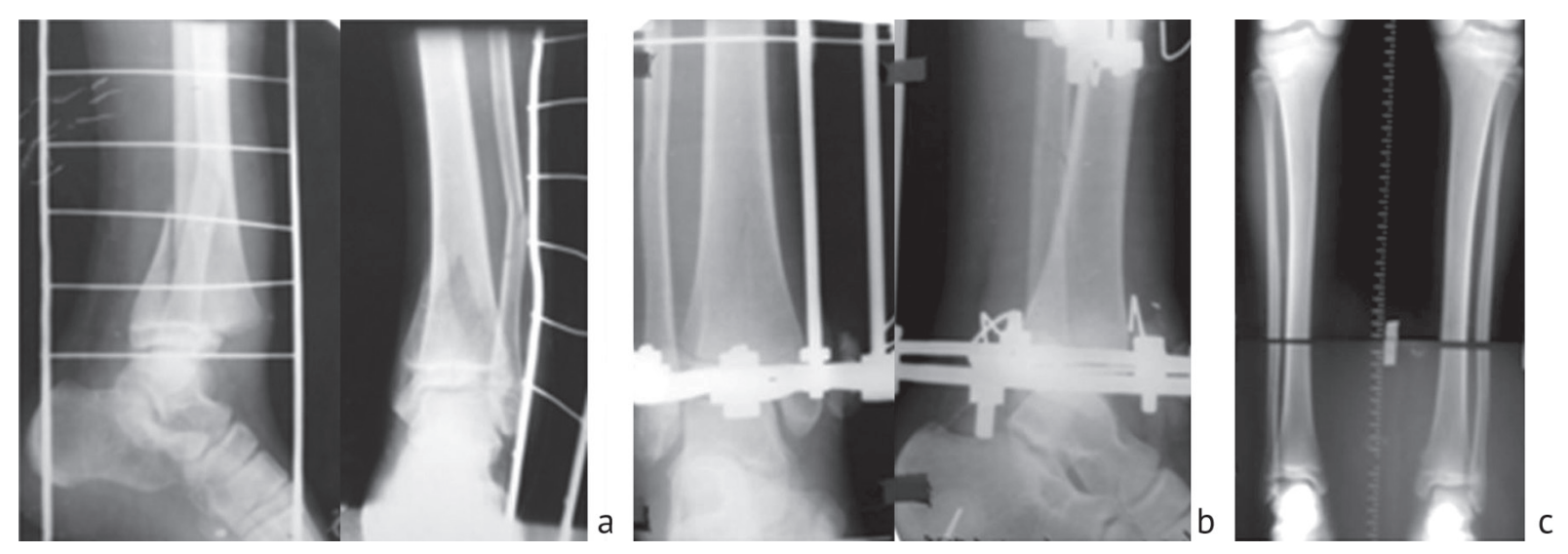

Fig. 5 Closed fracture of the distal epimetaphysis of the tibia (SH II). Radiographs taken in two projections: $\boldsymbol{a}$ before the operation; $\boldsymbol{b}$ after Ilizarov osteosynthesis; $\boldsymbol{c}$ after dismantling the Ilizarov apparatus

\section{DISCUSSION}

The available literature states that external fixation of pediatric supracondylar fractures is indicated for fracture types III and IV, when the use of standard percutaneous wire osteosynthesis cannot provide stable fixation, in cases of severe soft tissue edema of the elbow joint region, as well as in comminuted fractures and fractures with neurological or vascular complications [27, 28, 34, 35]. External fixation allows control of soft tissues condition in the fracture zone, and if necessary, may provide timely revision [32]. According to Gugenheim, the indications for the Ilizarov method are the impossibility of achieving adequate reduction due to the anterior displacement of the distal fragment, a long time interval since the injury, and the comminuted nature of the fracture [35]. On the other hand, conservative treatment is recommended for most type I and II fractures with the posterior cortex intact [20,26]. Percutaneous wire osteosynthesis and ESIN provide sufficient stability of bone fragments in simple fractures of types III, IV, and V [20, 28, 29, 31, 37]. Compared with percutaneous wire osteosynthesis, ESIN allows early motions in the elbow joint, excludes iatrogenic damage to nerves and blood vessels, and may be used in cases of significant edema and hematoma in the elbow joint [29, 31].

In our opinion, external fixation is not indicated in a simple periarticular distal fracture of the forearm bones. Its conservative treatment guarantees good functional and anatomical results $[15-17,38]$. However, it is known that distal fractures may be unstable, especially when comminuted. Closed reduction and immobilization with a plaster cast are associated with secondary displacement in up to $27 \%$ [19]. Chia et al also noted the high likelihood of secondary displacement with conservative treatment [15]. Ramoutar et al [37] observed a high complication rate $(17 \%)$ by studying the results after wire osteosynthesis.

Conservative treatment [7, 13], fixation with screws $[39,40]$, percutaneous wire osteosynthesis [40] and antegrade ESIN [29] are indicated for the treatment of uncomplicated distal juxta-articular femoral fractures. But the rate of early and long-term complications, according to the literature, is relatively high. Among them, the most common are damage to the ligaments of the knee joint, compartment syndrome, damage to neurovascular structures, and post-traumatic epiphyseodesis [21, 22, 41]. Complications after distal femoral epiphysiolysis occur in 37-70\% [40]. The Ilizarov method can be considered as the method of choice in the treatment of fractures of the distal femur for the following reasons it provides: adequate closed one-stage reduction, stable fixation, allowing early full axial load on the injured limb [12, 21, 39, 42].

In uncomplicated extra-articular distal fractures of the tibia, the Ilizarov method, in contrast to conventional methods of treating, allows early weightbearing of the injured limb $[46,47]$. These fractures are most common in older children and adolescents, when there is little time for remaining growth, and post-traumatic shortening or deformity will not lead to significant impairments [7, 43]. However, premature closure of the epiphyseal growth plate leads to clinically significant deformity in schoolchildren [45]. Özkul et al observed angular deformity associated with this complication in 20-60\% [14]. Currently, the optimal treatment for SH II fractures of the distal tibia has not been determined $[6,44]$.

\section{CONCLUSION}

General indications for the use of the Ilizarov method in children are comminuted, complicated and/ or open fractures, especially in the distal humerus, radius, femur and tibia.
The Ilizarov method, unlike other surgical methods for treating pediatric fractures, avoids additional damage to the growth plate, since the wires pass in a parallel plane; provides an adequate closed one-stage reduction 
of bone fragments, which preserves blood supply to the damaged tissues. The Ilizarov apparatus ensures the stability of fixation of fragments even in cases of comminuted fractures and the possibility, if necessary, of controlling the position of bone fragments throughout the treatment process. Early recovery of the function of the damaged segment and children's general activity also distinguish the Ilizarov method from other methods. Extra-focal fixation may be the method of choice for acute post-traumatic bone and soft tissue defects.

\section{REFERENCES}

1. Salter R.B., Harris W.R. Injuries involving the epiphyseal plate. J. Bone Joint Surg. Am., 1963, vol. 45, no. 3, pp. 587-622.

2. Bohn W.W., Durbin R.A. Ipsilateral fractures of the femur and tibia in children and adolescents. J. Bone Joint Surg. Am., 1991, vol. 73, no. 3, pp. 429-439.

3. Cannata G., De Maio F., Mancini F., Ippolito E. Physeal fractures of the distal radius and ulna: long-term prognosis. J. Orthop. Trauma, 2003, vol. 17, no. 3, pp. 172-179. DOI: 10.1097/00005131-200303000-00002.

4. Harley B.J., Scharfenberger A., Beaupre L.A., Jomha N., Weber D.W. Augmented external fixation versus percutaneous pinning and casting for unstable fractures of the distal radius - a prospective randomized trial. J. Hand Surg. Am., 2004, vol. 29, no. 5, pp. 815-824. DOI: 10.1016/j. jhsa.2004.05.006.

5. Franz T., Jandali A.R., Jung F.J., Leclère F.M., von Wartburg U., Hug U. Functional-conservative treatment of extra-articular physeal fractures of the proximal phalanges in children and adolescents. Eur. J. Pediatr. Surg., 2013, vol. 23, no. 4, pp. 317-321. DOI: 10.1055/s-0033-1333636.

6. Park H., Lee D.H., Han S.H., Kim S., Eom N.K., Kim H.W. What is the best treatment for displaced Salter-Harris II physeal fractures of the distal tibia? Acta Orthop., 2018, vol. 89, no. 1, pp. 108-112. DOI: 10.1080/17453674.2017.1373496.

7. Peterson H.A. Epiphyseal growth plate fractures. Berlin, Heidelberg, Springer-Verlag, 2007, 914 p. DOI: 10.1007/978-3-540-33802-4.

8. Valverde J.A., Albiñana J., Certucha J.A. Early posttraumatic physeal arrest in distal radius after a compression injury. J. Pediatr. Orthop. B, 1996, vol. 5, no. 1, pp. 57-60. DOI: 10.1097/01202412-199605010-00012.

9. Franz T., von Wartburg U., Schibli-Beer S., Jung F.J., Jandali A.R., Calcagni M., Hug U. Extra-articular fractures of the proximal phalanges of the fingers: a comparison of 2 methods of functional, conservative treatment. J. Hand Surg. Am., 2012, vol. 37, no. 5, pp. 889-898. DOI: 10.1016/j. jhsa.2012.02.017.

10. Joeris A., Lutz N., Blumenthal A., Slongo T., Audigé L. The AO pediatric comprehensive classification of long bone fractures (PCCF). Acta Orthop., 2017, vol. 88, no. 2, pp. 129-132. DOI: 10.1080/ 17453674.2016.1258533.

11. Audigé L., Slongo T., Lutz N., Blumenthal A., Joeris A. The AO pediatric comprehensive classification of long bone fractures (PCCF). Acta Orthop., 2017, vol. 88, no. 2, pp. 133-139. DOI: 10.1080/ 17453674.2016.1258534.

12. Anari J.B., Neuwirth A.L., Horn B.D., Baldwin K.D. Ipsilateral femur and tibia fractures in pediatric patients: a systematic review. World J. Orthop., 2017, vol. 8, no. 8, pp. 638-643. DOI: 10.5312/wjo.v8.i8.638.

13. Karlikowski M., Sułko J. Physeal fractures of the lower leg in children and adolescents: therapeutic results, pitfalls and suggested management protocol based on the experience of the authors and contemporary literature. Adv. Med. Sci., 2018, vol. 63, no. 1, pp. 107-111. DOI: 10.1016/j. advms.2017.10.001.

14. Özkul B., Saygılı M.S., Çetinkaya E., Arslanoğlu F., Bayhan I.A., Demir B., Tekin A.C. Angular deformity development after the distal tibial physeal fractures. Acta Orthop. Belg., 2016, vol. 82, no. 4, pp. 814-820.

15. Chia B., Kozin S.H., Herman M.J., Safier S., Abzug J.M. Complications of pediatric distal radius and forearm fractures. Instr. Course Lect., 2015, vol. 64, pp. 499-507.

16. Dua K., Abzug J.M., Sesko Bauer A., Cornwall R., Wyrick T.O. Pediatric distal radius fractures. Instr. Course Lect., 2017, vol. 66, pp. 447-460.

17. Otayek S., Ramanoudjame M., Fitoussi F. Les fractures de l'extrémité distale du radius chez l'enfant [Distal radius fractures in children]. Hand Surg. Rehabil., 2016, vol. 35S, pp. S150-S155. DOI: 10.1016/j.hansur.2016.02.013. (in French)

18. Larsen M.C., Bohm K.C., Rizkala A.R., Ward C.M. Outcomes of nonoperative treatment of Salter-Harris II distal radius fractures: a systematic review. Hand (N Y), 2016, vol. 11, no. 1, pp. 29-35. DOI: 10.1177/1558944715614861.

19. Jordan R.W., Westacott D., Srinivas K., Shyamalan G. Predicting redisplacement after manipulation of paediatric distal radius fractures: the importance of cast moulding. Eur. J. Orthop. Surg. Traumatol., 2015, vol. 25, no. 5, pp. 841-845. DOI: 10.1007/s00590-015-1627-0.

20. Hill C.E., Cooke S. Common paediatric elbow injuries. Open Orthop. J., 2017, vol. 11, pp. 1380-1393. DOI: 10.2174/ 1874325001711011380.

21. Javanović V., Vukasinović Z., Seslija I. [Complicated distal femoral epiphyseolysis treated by Ilizarov method: case report]. Srp. Arh. Celok. Lek., 2010, vol. 138, no. 5-6, pp. 367-370. (in Serbian) DOI: 10.2298/sarh1006367j.

22. Eid A.M., Hafez M.A. Traumatic injuries of the distal femoral physis. Retrospective study on 151 cases. Injury, 2002, vol. 33 , no. 3, pp. $251-255$. DOI: $10.1016 / \mathrm{s} 0020-1383(01) 00109-7$.

23. Skaggs D.L., Hale J.M., Buggay S., Kay R.M. Use of a hybrid external fixator for a severely comminuted juxta-articular fracture of the distal humerus. J. Orthop. Trauma, 1998, vol. 12, no. 6, pp. 439-442. DOI: 10.1097/00005131-199808000-00015.

24. Manoj Kumar P.P., Salgotra K.R. Clinico-radiological evaluation of juxta articular fractures and diaphyseal fractures of upper limb managed with locking compression plating. Med. J. Armed Forces India, 2012, vol. 68, no. 3, pp. 211-213. DOI: 10.1016/j.mjafi.2012.03.008.

25. Reyes F.A., Latta L.L. Conservative management of difficult phalangeal fractures. Clin. Orthop. Relat. Res., 1987, no. 214, pp. 23-30.

26. Lagrange J., Rigault P. Fractures supracondyliennes [Supracondylar fractures]. Rev. Chir. Orthop., 1962, vol. 48, pp. 337-414. (in French)

27. Zhao C. [Outcomes of different operations for distal forearm fractures in children]. Zhonghua Yi Xue Za Zhi, 2015, vol. 95, no. 15, pp. 1168-1170. (in Chinese) DOI: 10.3760/cma.j.issn.0376-2491.2015.15.012.

28. Spiegel P.G., Mast J.W. Internal and external fixation of fractures in children. Orthop. Clin. North Am., 1980, vol. 11, no. 3, pp. 405-421.

29. Lascombes P. Flexible intramedullary nailing in children. The Nancy University manual. Berlin, Heidelberg, Springer-Verlag, 2010.

30. Lascombes P., Huber H., Fay R., Popkov D., Haumont T., Journeau P. Flexible intramedullary nailing in children: nail to medullary canal diameters optimal ratio. J. Pediatr. Orthop., 2013, vol. 33, no. 4, pp. 403-408. DOI: 10.1097/ BPO.0b013e318285c54d.

31. Prévot J., Lascombes P., Métaizeau J.P., Blanquart D. Fractures supra-condyliennes de l'humérus de l'enfant: traitement par embrochage descendant [Supracondylar fractures of the humerus in children: treatment by downward nailing]. Rev. Chir. Orthop. Reparatrice Appar. Mot., 1990, vol. 76, no. 3, pp. 191-197. (in French)

32. Or O., Weil Y., Simanovsky N., Panski A., Goldman V., Lamdan R. The outcome of early revision of malaligned pediatric supracondylar humerus fractures. Injury, 2015, vol. 46, no. 8, pp. 1585-1590. DOI: 10.1016/j. injury.2015.04.022.

33. Eberl R., Weinberg A.M. Posttraumatische Korrekturoperationen am kindlichen Ellenbogen [Operative corrections of posttraumatic deformities of the elbow joint in children]. Unfallchirurg, 2010, vol. 113, no. 2, pp. 139-148. DOI: 10.1007/s00113-009-1728-1725. (in German)

34. Slongo T. Radialer externer Fixateur zur geschlossenen Behandlung problematischer suprakondylärer Humerusfrakturen Typ III und IV bei Kindern und Jugendlichen. Eine neue chirurgische Technik [Radial external fixator for closed treatment of type III and IV supracondylar humerus fractures in children. A new surgical technique]. Oper. Orthop. Traumatol., 2014, vol. 26, no. 1, pp. 75-96. (in German) DOI: 10.1007/ s00064-013-0291-y.

35. Gugenheim J.J. Jr. The Ilizarov fixator for pediatric and adolescent supracondylar fracture variants. J. Pediatr. Orthop., 2000, vol. 20, no. 2, pp. 177-182.

36. Prashant K., Lakhotia D., Bhattacharyya T.D., Mahanta A.K., Ravoof A. A comparative study of two percutaneous pinning techniques (lateral vs medial-lateral) for Gartland type III pediatric supracondylar fracture of the humerus. J. Orthop. Traumatol., 2016, vol. 17, no. 3, pp. 223-229. DOI: $10.1007 / \mathrm{s} 10195-016-0410-2$. 
37. Hohloch L., Konstantinidis L., Wagner F.C., Strohm P.C., Südkamp N.P., Reising K. Biomechanical comparison of different external fixator configurations for stabilization of supracondylar humerus fractures in children. Clin. Biomech. (Bristol, Avon), 2016, vol. 32, pp. 118-123. DOI: 10.1016/j. clinbiomech.2015.12.003.

38. Ramoutar D.N., Shivji F.S., Rodrigues J.N., Hunter J.B. The outcomes of displaced paediatric distal radius fractures treated with percutaneous Kirschner wire fixation: a review of 248 cases. Eur. J. Orthop. Surg. Traumatol., 2015, vol. 25, no. 3, pp. 471-476. DOI: 10.1007/s00590-0141553-6.

39. Wójcik K., Wojciechowski P., Kusz D. Leczenie operacyjne urazowego uszkodzenia dalszej nasady kości udowej typu II wg Saltera-Harrisa [Surgical treatment for Salter-Harris type II distal femoral epiphysis injury]. Chir. Narzadow Ruchu Ortop. Pol., 1998, vol. 63, no. 2, pp. 143-149. (in Polish)

40. Oberle M., Bonetta M., Schlickewei W. Operative Therapie der kniegelenknahen Epiphyseolyse [Surgical treatment of epiphysiolyses of the distal femur and the proximal tibia]. Oper. Orthop. Traumatol., 2008, vol. 20, no. 4-5, pp. 387-395. DOI: 10.1007/s00064-008-1410-z. (in German)

41. Edgard-Rosa G., Launay F., Glard Y., Guillaume J.M., Jouve J.L., Bollini G. Fractures-décollements épiphysaires de type SalterII de l'extrémité distale du fémur chez l'adolescent : nouvelle proposition thérapeutique (étude préliminaire) [Salter and Harris type-II distal femoral physeal fractureseparations at adolescent age: a new therapeutic approach (preliminary study)]. Rev. Chir. Orthop. Reparatrice Appar. Mot., 2008, vol. 94, no. 6, pp. 546-551. (in French) DOI: 10.1016/j. rco.2008.01.007.

42. Wei S.W., Shi Z.Y., Hu J.Z., Wu H. [Treatment of pediatric distal femur fractures by external fixator combined with limited internal fixation]. Zhongguo Gu Shang, 2016, vol. 29, no. 3, pp. 275-278. (in Chinese)

43. Popkov D., Lascombes P., Berte N., Hetzel L., Baptista B.R., Popkov A., Journeau P. The normal radiological anteroposterior alignment of the lower limb in children. Skeletal Radiol., 2015, vol. 44, no. 2, pp. 197-206. DOI: 10.1007/ s00256-014-1953-z.

44. D'Angelo F., Solarino G., Tanas D., Zani A., Cherubino P., Moretti B. Outcome of distal tibia physeal fractures: a review of cases as related to risk factors. Injury, 2017, vol. 48, no. Suppl. 3, pp. S7-S11. DOI: 10.1016/S0020- 1383(17)30650-2.

45. Barmada A., Gaynor T., Mubarak S.J. Premature physeal closure following distal tibia physeal fractures: a new radiographic predictor. J. Pediatr. Orthop., 2003, vol. 23, no. 6, pp. 733-739. DOI: 10.1097/00004694-200311000-00010.

46. Korobeinikov A., Popkov D. Use of external fixation for juxta-articular fractures in children. Injury, 2019, vol. 50, no. Suppl. 1, pp. S87-S94. DOI: 10.1016/j.injury.2019.03.043.

47. Sysenko Iu.M., Nasyrov M.Z. Lechenie detei s epi- i osteoepifizeolizami dlinnykh trubchatykh kostei metodom chreskostnogo osteosinteza po Ilizarovu [Treatment of children with epi- and osteoepiphysiolyses of long tubular bones using the transosseous osteosynthesis technique according to Ilizarov]. Genij Ortopedii, 2001, no. 4, pp. 92-96. (in Russian)

Received: 28.06 .2021

\section{Information about the authors:}

1. Anatoly A. Korobeinikov, M.D., Ph.D., Ilizarov National Medical Research Centre for Traumatology and Orthopedics, Kurgan, Russian Federation, Kurgan Regional Children's Clinical Hospital named after the Red Cross, Kurgan, Russian Federation

2. Anna M. Aranovich, M.D., Ph.D., Professor,

Ilizarov National Medical Research Centre for Traumatology and Orthopedics, Kurgan, Russian Federation, Email: aranovich_anna@mail.ru

3. Dmitry A. Popkov, M.D., Ph.D., Professor of RAS, correspondent member French Academy of Medical Sciences, Ilizarov National Medical Research Centre for Traumatology and Orthopedics, Kurgan, Russian Federation, Email:dpopkov@mail.ru 